\title{
Factors affecting variations in the detailed fatty acid profile of Mediterranean buffalo milk determined by 2-dimensional gas chromatography
}

\author{
S. Pegolo, ${ }^{*}$ G. Stocco, ${ }^{*}$ M. Mele, $†$ S. Schiavon, ${ }^{*}$ G. Bittante, ${ }^{*}$ and A. Cecchinato*1 \\ *Department of Agronomy, Food, Natural Resources, Animals and Environment (DAFNAE), University of Padova, Viale dell'Università 16, \\ 35020 Legnaro, Padova, Italy \\ †Department of Agriculture, Food and Environment, Università di Pisa, Via del Borghetto, 80, 56124 Pisa, Italy
}

\begin{abstract}
Buffalo milk is the world's second most widely produced milk, and increasing attention is being paid to its composition, particularly the fatty acid profile. The objectives of the present study were (1) to characterize the fatty acid composition of Mediterranean buffalo milk, and (2) to investigate potential sources of variation in the buffalo milk fatty acid profile. We determined the profile of 69 fatty acid traits in 272 individual samples of Mediterranean buffalo milk using gas chromatography. In total, 51 individual fatty acids were identified: 24 saturated fatty acids, 13 monounsaturated fatty acids, and 14 polyunsaturated fatty acids. The major individual fatty acids in buffalo milk were in the order 16:0, 18:1 cis-9, 14:0, and 18:0. Saturated fatty acids were the predominant fraction in buffalo milk fat (70.49\%); monounsaturated and polyunsaturated fatty acids were at 25.95 and $3.54 \%$, respectively. Adopting a classification based on carbon-chain length, we found that medium-chain fatty acids (11-16 carbons) represented the greater part $(53.7 \%)$ of the fatty acid fraction of buffalo milk, whereas long-chain fatty acids (17-24 carbons) and short-chain fatty acids (4-10 carbons) accounted for 32.73 and $9.72 \%$, respectively. The n-3 and n- 6 fatty acids were 0.46 and $1.77 \%$, respectively. The main conjugated linoleic acid, rumenic acid, represented $0.45 \%$ of total milk fatty acids. Herd/test date and stage of lactation were confirmed as important sources of variation in the fatty acid profile of buffalo milk. The percentages of short-chain and medium-chain fatty acids in buffalo milk increased in early lactation $(+0.6$ and $+3.5 \%$, respectively), whereas long-chain fatty acids decreased $(-4.2 \%)$. The only exception to this pattern was butyric acid, which linearly decreased from the beginning of lactation, confirmation that its
\end{abstract}

Received July 4, 2016

Accepted December 15, 2016.

${ }^{1}$ Corresponding author: alessio.cecchinato@unipd.it synthesis is independent of malonyl-CoA. These results seem to suggest that in early lactation the mobilization of energy reserves may have less influence on the fatty acid profile of buffalo milk than that of cow milk, probably due to a shorter and less severe period of negative energy balance. Parity affected the profiles of a few traits and had the most significant effects on branchedchain fatty acids. This work provided a detailed overview of the fatty acid profile in buffalo milk including also those fatty acids present in small concentrations, which may have beneficial effects for human health. Our results contributed also to increase the knowledge about the effects of some of the major factors affecting buffalo production traits and fatty acid concentrations in milk, and consequently its technological and nutritional properties.

Key words: Mediterranean buffalo, milk fatty acid, 2-dimensional gas chromatography, sources of variation

\section{INTRODUCTION}

The buffalo (Bubalus bubalis) is the world's second largest source of milk, producing 102 billion liters each year $(13.3 \%$ of all milk produced vs. 636 billion liters of cow milk, $82.7 \%$ of the total) (FAOSTAT, 2013). Buffalo milk is a rich source of nutrients and therefore plays an important role in human nutrition, particularly in developing countries (e.g., $\sim 70 \%$ of buffalo milk is produced in India; FAOSTAT 2013). Indeed, buffalo milk has higher contents of protein and fat (Ahmad et al., 2013) and minerals (Stocco et al., 2016) than cow milk, whereas some specific classes of gangliosides seem to be only present in buffalo milk (Colarow et al., 2003). The high fat content of buffalo milk makes it also highly suitable for processing (Menard et al., 2010), and in developed countries it is mainly used for the production of a variety of foodstuffs, such as butter, butter oil (ghee), soft and hard cheeses, condensed and evaporated milk, ice cream, yogurt, buttermilk, and in Italy, the highly popular buffalo mozzarella obtained under the European Union's protected designation of origin scheme. 
Buffalo dairy farms in Italy are traditionally concentrated in the Campania region where the Protected Designation of Origin cheese "Mozzarella di Bufala Campana" is produced. Recently, however, the demand for buffalo mozzarella has greatly increased, resulting in increasing numbers of buffaloes (Hanaa et al., 2015) and considerable expansion in buffalo farming even into the northern regions of Italy (Tiezzi et al., 2009).

Over the last decade, many studies have been done on the fatty acid composition of bovine milk fat (MF) due to its potential beneficial or negative effects on human health. For instance, CLA has been shown to have anticarcinogenic, antiobesity, antidiabetic, and antihypertensive properties in humans (Koba and Yanagita, 2014), as well as beneficial effects for reproductive performance and carcass traits in ruminants (Mir et al., 2000). Furthermore, the effects of the large groups of fatty acids (e.g., saturated vs. unsaturated, n-3 vs. n-6) on the cardiovascular system have been challenged by recent meta-analyses (Siri-Tarino et al., 2010; de Souza et al., 2015). Indeed, more attention has being paid to the effect of individual fatty acids on human health and disease instead of macro-categories, and novel roles for specific fatty acids have been (and probably will be) proposed. Thereby, it would be desirable to obtain a comprehensive profile of fatty acids in the various food matrices (e.g., milk), including those less known, present in small concentrations, or both.

To our knowledge, the available studies aimed at evaluating the fatty acid profile of buffalo milk have been carried out on a relatively small number of animals (e.g., Menard et al., 2010; Zotos and Bampidis, 2014) or considered only the most representative and well-known fatty acids groups and individual fatty acids (e.g., Tonhati et al., 2011).

Therefore, the aims of this work were (1) to determine by $\mathrm{GC} \times \mathrm{GC}$ (2-dimensional GC) the detailed milk fatty acid profile in a large number of Mediterranean buffaloes; and (2) to evaluate potential sources of variation affecting the profiles of the identified milk fatty acid traits.

\section{MATERIALS AND METHODS}

\section{Animals and Sampling}

Milk samples were collected once during the evening milking from 272 buffaloes reared under intensive farming conditions in 6 herds located in northern Italy from January to May 2013. Farms and facilities were comparable to those characterizing the dairy herds in northern Italy with open barns, loose animals, and milking parlors. Buffaloes were fed year-round TMR based on corn silage, cereals, grass hay, wheat straw, and protein meals, supplemented with vitamins and minerals [i.e., the same ingredients of the TMR diets of dairy cows reared in a the same geographical area, the Po valley (Dal Maso et al., 2009)]. The number of animals sampled from each herd were 81, 31, 30, 60, 30, and 40. Animals were selected from each herd to represent all lactation stages and a range of parities. Each buffalo was given a BCS by a trained operator, according to Edmonson et al. (1989). The milk samples (no preservative was added) were immediately refrigerated at $4^{\circ} \mathrm{C}$ and transferred to the Cheese-Making Laboratory of the Department of Agronomy, Food, Natural Resources, Animals and Environment of the University of Padua (Legnaro, Padua, Italy).

Data on the buffaloes, herds, and single test-day milk yields (MY) were provided by the breeders' associations of the Veneto and Friuli Venezia-Giulia regions.

\section{Lipid Extraction and Gas Chromatography Analysis}

Milk fat was extracted from milk subsamples $(5 \mathrm{~mL})$ by accelerated solvent extraction (ASE 200, Dionex Corp., Sunnyvale, CA). After thawing, samples were homogenized using a Hydromatrix (Agilent Technologies, Santa Clara, CA) and transferred to 22-mL stainless steel extraction cells for ASE extraction using petroleum ether:isopropanol (2:1, vol/vol). The extraction conditions were as follows: temperature, $120^{\circ} \mathrm{C}$; pressure, $10.34 \mathrm{MPa}$; static time, $1 \mathrm{~min}$; number of static cycles, 3. Solvent evaporation was carried out under vacuum $\left(37^{\circ} \mathrm{C}\right)$ using a Rotavapor (Rotavapor1 R-205, Buchi Italia s.r.l., Cornaredo, Italy). The extracted fat was weighed and subsamples of about $40 \mathrm{mg}$ were transferred to culture tubes for immediate transesterification and methylation, according to Christie (2001), using $1 M$ sodium methoxide in methanol at room temperature. Methyl 12-tridecenoate was used as an internal standard (\#U-35 M, Nu-Chek Prep Inc., Elysian, MN). The resulting FAME solution was stored at $-20^{\circ} \mathrm{C}$ before $\mathrm{GC}$ analysis.

The fatty acid profiles of the samples obtained were analyzed using a GC $\times$ GC instrument (Agilent 7890A, Agilent Technologies) equipped with a modulator (Agilent G3486ACFT), an automatic sampler (Agilent 7693), and a flame-ionization detector connected to chromatography data system software (Agilent Chem Station). Two columns in series were used to obtain better separation and identification of fatty acids: first column $75 \mathrm{~m} \times 180 \mu \mathrm{m}$ (internal diameter) $\times 0.14 \mu \mathrm{m}$ film thickness (SP-2560, 23348U, Supelco, Bellefonte, $\mathrm{PA}$ ); second column $3.8 \mathrm{~m} \times 250 \mu \mathrm{m}$ (internal diameter) $\times 0.25 \mu \mathrm{m}$ film thickness (HP-5MS, J\&W 19091S- 
431, Agilent Technologies). Operating conditions and GC reference standards have been previously reported in detail (Pellattiero et al., 2015). We detected different peaks in the region of the 18:1 isomers, and experienced problems of partial co-elution in some samples: 18:1 trans- 6 with 18:1 trans-8, and 18:1 trans-9 (elaidic acid) with 18:1 trans-10 and 18:1 trans-11 (vaccenic acid; VA). Therefore, in those cases the percentages reported relate to the sum of all the co-eluted isomers. Milk fatty acid composition is expressed as grams per $100 \mathrm{~g}$ of total fatty acids. We report here only the fatty acids accounting for more than $0.02 \%$.

\section{Statistical Analysis}

Sources of variation in the fatty acid traits were investigated using the SAS 9.4 MIXED procedure (SAS Inst. Inc., Cary, NC), using the following linear model:

$$
y_{i j k l}=\mu+\operatorname{DIM}_{i}+\operatorname{parity}_{j}+\operatorname{herd}_{k}+\mathrm{e}_{i j k l}
$$

where $y_{i j k l}$ is the observed trait (production trait, BCS, individual fatty acid, fatty acid group, unsaturation index); $\mu$ is the overall intercept of the model; $\mathrm{DIM}_{i}$ is the fixed effect of the $i$ th class of DIM $[i=1$ to 7 ; class 1 , DIM <30 ( $\mathrm{n}=23)$; class 2, DIM 30-60 ( $\mathrm{n}=28)$; class 3, DIM 60-120 $(\mathrm{n}=43)$; class 4, DIM 120-180 (n $=48)$; class 5, DIM 180-239 $(\mathrm{n}=32)$; class 6, DIM 239-298 ( $\mathrm{n}=47)$; class 7, DIM >298 $(\mathrm{n}=51)$ ]; parity $_{j}$ is the fixed effect of the $j$ th parity of the buffalo $(j=1$ to 5 or more; with number of buffaloes equal to 49,83 , 54, 34, and 52 for first, second, third, fourth, and fifth or more parity order, respectively); herd ${ }_{k}$ is the random effect of the $k$ th herd/test date (HTD; $k=1$ to 6 ); and $\mathrm{e}_{i j k l}$ is the random residual. The HTD and residuals were assumed to be independently and normally distributed with means equal to zero and variances of $\sigma_{H}^{2}$ and $\sigma_{e}^{2}$, respectively. The percentage of variance explained by HTD was calculated by dividing the corresponding component of variance by the total variance.

Those fatty acids that included a high number of missing values were excluded from the analyses using the general linear model because estimates of the effects of DIM, parity, and HTD would not be accurate if the various DIM or parity classes or herds were not all well represented.

Polynomial contrasts were estimated $(P<0.05)$ between the least squares means of the effects of DIM (i.e., first-order comparisons measured linear relationships, whereas second- and third-order comparisons measured quadratic and cubic relationships, respectively).

\section{RESULTS}

\section{Descriptive Statistics}

The results for production traits and fatty acid compositions, groups, and indices in Mediterranean buffalo milk are reported in Tables 1 and 2 .

Milk yield averaged $7.03 \mathrm{~kg} / \mathrm{d}$ and the MF content averaged $7.81 \%$. The variation in MY was high ( SD = 4.09 ), around double that of the MF percentage (SD = 2.30). The average BCS score was 3.93 (Table 1).

The GC analysis determined 51 individual fatty acids: 24 SFA, 13 MUFA, and 14 PUFA (Table 1). The standard deviation values were high, reflecting the high variability observed in these traits. The major fatty acids in buffalo milk were in the order 16:0, 18:1 cis-9, 14:0, and 18:0). Butyric acid (4:0) was the most abundant short-chain fatty acid (SCFA) in buffalo milk. Linoleic acid (18:2 cis-9, cis-12) was the major n-6 fatty acid, and linolenic acid (18:3 cis-9,cis-12,cis-15) was the major n-3. The main CLA, rumenic acid (RA, 18:2 cis-9,trans-11), represented $0.45 \%$ of total fatty acids in buffalo milk (Table 1).

Saturated fatty acids were the predominant fraction in buffalo MF (70.49\%); MUFA and PUFA were 25.95 and $3.54 \%$, respectively. Considering the classification based of the carbon chain length: medium-chain fatty acids (MCFA) represented the greater part (53.70\%) of the buffalo milk fatty acid fraction, whereas longchain fatty acids (LCFA) and SCFA represented 32.73 and $9.72 \%$, respectively. Total n-3 and n- 6 fatty acids were 0.46 and $1.77 \%$, respectively, whereas the $n-6 / n-3$ ratio was 3.89 (Table 2).

Among the unsaturation indices, the $\mathrm{C} 18$ index had the highest mean percentage (67.64\%), followed by the CLA index $(23.37 \%)$. The percentages of the short-chain desaturation index (10:1) and the mediumchain desaturation indices (14:1 and 16:1) were smaller (Table 2).

\section{Factors Affecting Production Traits and Milk Fatty Acid Secretion in Buffalo}

Tables 3 and 4 show the results from the linear model used to explain the role of DIM, parity, and HTD on production traits and the fatty acid profile of buffalo milk.

Effect of Herd/Test Date. The HTD was confirmed as an important source of variation in production traits and the fatty acid profile of buffalo milk (Tables 3 and 4). In particular, we observed high HTD percentages for MY and MF content (61.7 and 50.2\%, respectively; Table 3). Regarding individual fatty ac- 
Table 1. Descriptive statistics for buffalo milk production traits and individual fatty acids $(\mathrm{n}=272)$

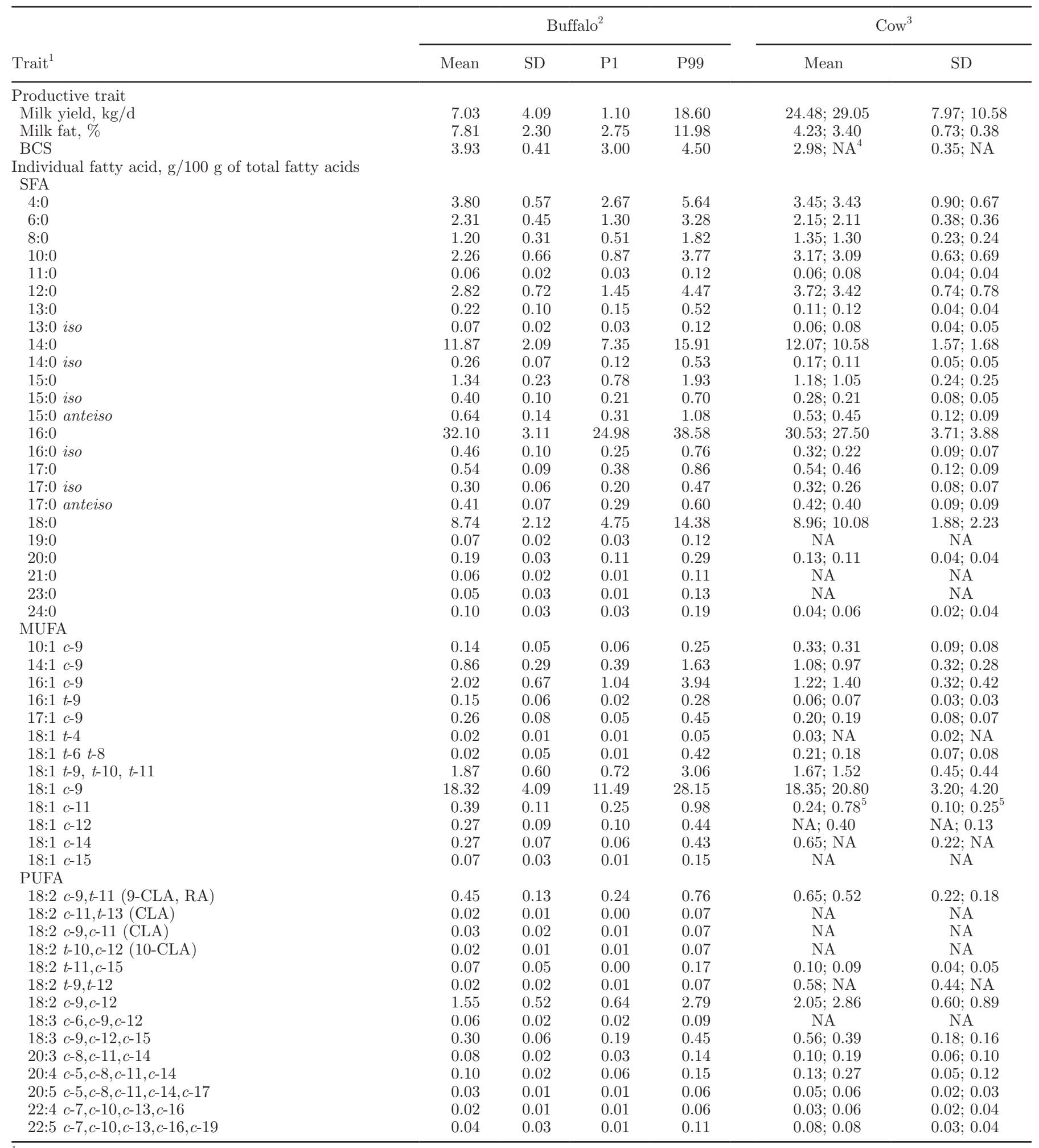

${ }^{1} c=$ cis; $t=$ trans. BCS was determined according to Edmonson et al. (1989). RA = rumenic acid.

${ }^{2}$ Present study. $\mathrm{P} 1=1$ st percentile. P99 = 99th percentile.

${ }^{3}$ Pegolo et al. (2016) on Brown Swiss cows; Conte et al. (2016) on Holstein Friesian cows.

${ }^{4} \mathrm{NA}=$ not available.

${ }^{5}$ Sum of 18:1 $c-11$ and 18:1 $t-15$ (Conte et al., 2016). 
Table 2. Descriptive statistics for groups of fatty acids, and indices $(\mathrm{n}=272)$

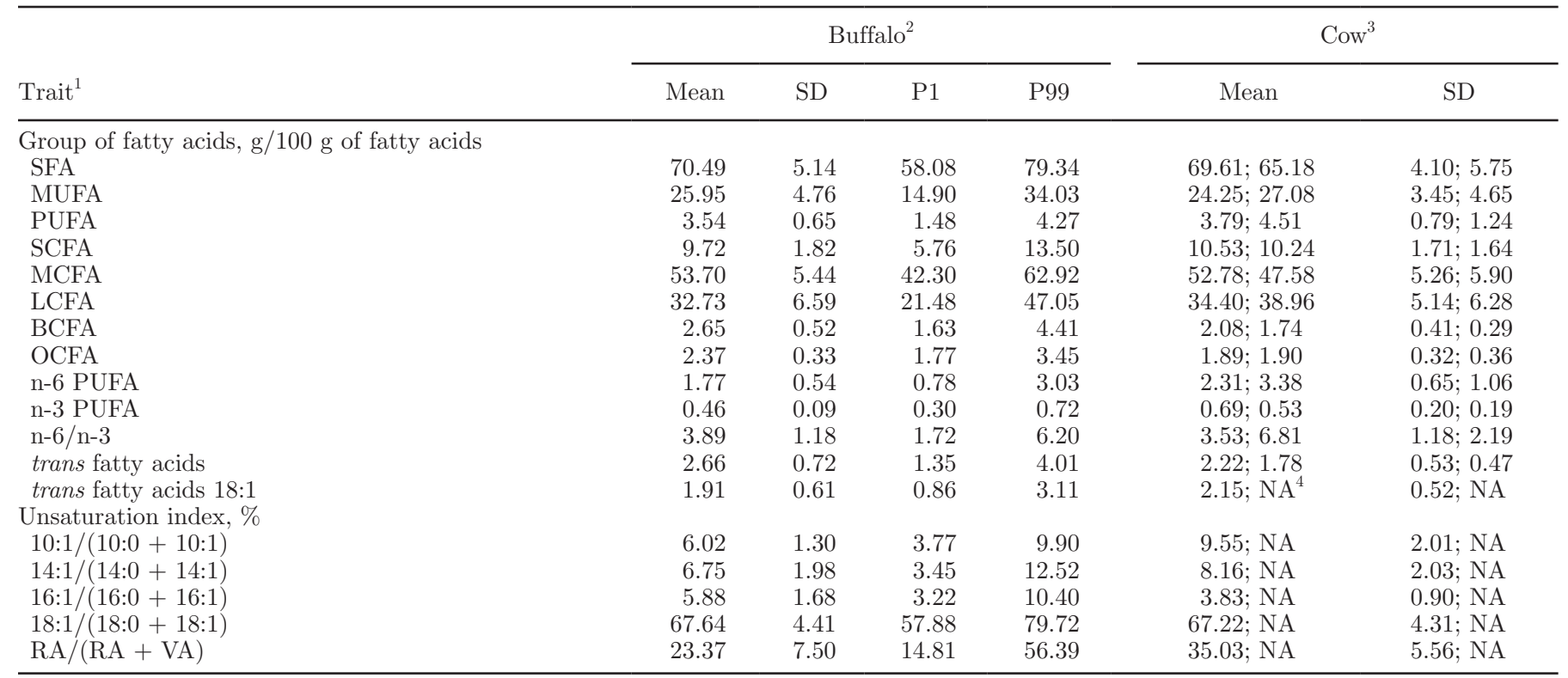

${ }^{1} \mathrm{SCFA}=$ short-chain fatty acids; MCFA = medium-chain fatty acids; LCFA = long-chain fatty acids; BCFA = branched-chain fatty acids; OCFA = odd-chain fatty acids; $\mathrm{RA}=$ rumenic acid; $\mathrm{VA}=$ vaccenic acid. SCFA included the 4:0, 6:0, 8:0, and 10:1 fatty acids; MCFA included all linear fatty acids from 11:0 to 16:1; LCFA included all linear fatty acids from 17:0 to 24:0; trans fatty acids included all trans fatty acids; trans fatty acids 18:1 included all trans isomers of 18:1.

${ }^{2}$ Present study. $\mathrm{P} 1=1$ st percentile. P99 = 99th percentile.

${ }^{3}$ Pegolo et al. (2016) on Brown Swiss cows; Conte et al. (2016) on Holstein Friesian cows.

${ }^{4} \mathrm{NA}=$ not available.

ids, we found moderate HTD percentages $(>30 \%)$ for most MCFA, branched-chain fatty acids (BCFA), and LCFA (Table 3). Overall, total PUFA, n-6 fatty acids, total trans fatty acids, and total trans 18:1 fatty acids had the highest HTD percentages (around 70\%; Table 4), whereas SCFA had the lowest (Tables 3 and 4). Among the desaturation indices, we found 10:1, 14:1, and 18:1 to have lower HTD percentages $(<30 \%)$, and the 16:1 and CLA indices to have slightly higher HTD percentages.

Effect of Parity. Parity significantly affected MY but not the fat content of buffalo milk (Table 3). Overall, parity had significant effects on a few fatty acid traits, in particular the individual and total proportions of BCFA, and total SFA, MUFA, MCFA, and odd-chain fatty acids (OCFA; Tables 3 and 4). Parity significantly affected the individual proportions of 16:0, 17:0, 23:0, 16:1 trans-9 and 18:1 cis-11, and of the n-3 fatty acids $22: 5$ cis-7,cis-10,cis-13,cis-16,cis-19, and 18:3 cis-9, cis-12, cis-15 (Table 3 ).

Effect of DIM. As expected, stage of lactation significantly affected the MY, BCS, and MF percentages (Table 3). Body condition scores increased linearly during lactation $(P<0.001$, estimated by orthogonal contrasts) (Figure 1a). The trend of the MY is in the opposite direction to the BCS curve (linear decrease,
$P<0.001$; Figure $1 \mathrm{~b})$. The MF had a cubic trend $(P$ $<0.01$, estimated by polynomial contrasts; Figure 1c) with percentages always greater than $7 \%$ throughout lactation. Stage of lactation was confirmed as an important source of variation in almost all the fatty acid traits with only a few exceptions (Tables 3 and 4 ). Individually, 6:0, 14:0, and 18:1 cis-9 were the fatty acids most significantly affected (Table 3). Overall, SFA, MUFA, SCFA, and the 10:1, 14:1, and 16:1 indices also had the highest $F$-values (Table 4 ). The total SFA data had a quadratic trend $(P<0.001$, estimated by polynomial contrasts), with an increase during the first 120 DIM followed by a decrease (Figure 2a). Individually, most of the linear SFA share this trend (Table 3). Short-chain fatty acids and MCFA also followed the same pattern (quadratic component, $P<0.001$ ), the greatest variations being found with MCFA (Table 4, Figures 3a and 3b). Overall, the trends of MUFA, PUFA, and LCFA were in the opposite direction, with a slight reduction in the first 120 DIM, then increasing with advancing lactation (Table 4, Figures 2b, 2c, and $3 c$ ). These patterns clearly reflect those of the most abundant individual fatty acids in each of these groups (i.e., 18:1 cis-9 for MUFA; 18:1 cis-9 and 18:0 for LCFA and 18:2 cis-9,cis-12 for PUFA; Table 3). Unlike total SCFA, butyric acid (4:0) decreased linearly from the 
Table 3. Results from ANOVA ( $F$-value and significance) for production traits and individual fatty acid profile in buffalo milk

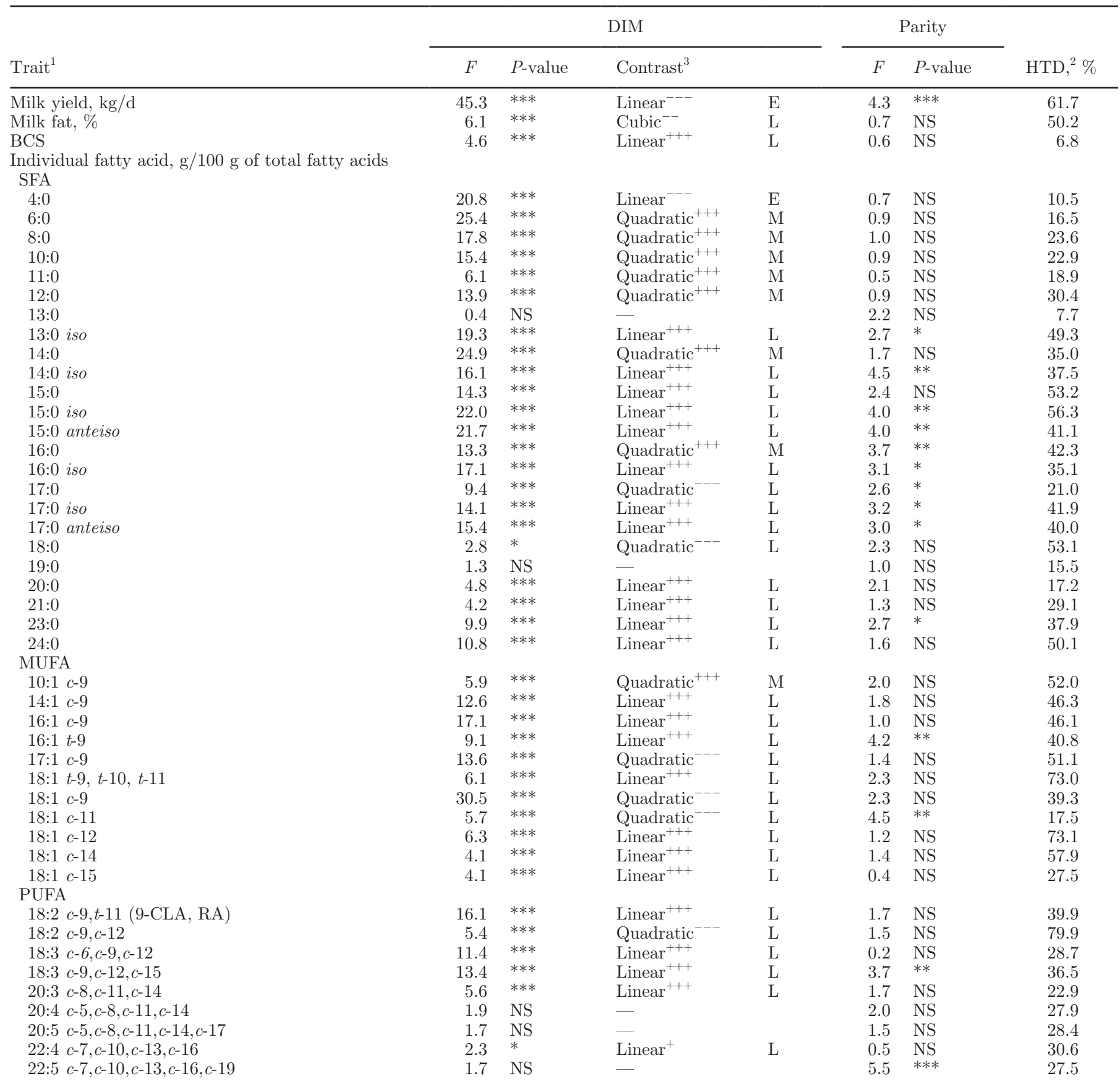

${ }^{1} c=$ cis; $t=$ trans. BCS was determined according to Edmonson et al. (1989). RA = rumenic acid.

${ }^{2}$ Herd/test date (HTD) effect expressed as proportion of variance explained by HTD calculated by dividing the corresponding variance component by the total variance.

${ }^{3+/-}$ : Refers to the trend direction of fatty acid trait LSM over lactation (linear, quadratic, or cubic) ( $^{+/} P<0.05 ;^{++/--} P<0.01 ;^{+++/---} P<$ 0.001. E, M, L: highest percentages in early (E), mid (M), or late (L) lactation.

${ }^{*} P<0.05 ;{ }^{* *} P<0.01 ;{ }^{* * *} P<0.001$.

beginning of lactation $(P<0.001$; Table 3, Figure 3a), whereas total n-3 and n- 6 fatty acids increased linearly with advancing lactation $(P<0.001$; Table 4$)$. We also found the latter trend with RA $(P<0.001$; Figure 4 and Table 3), total trans fatty acids, 18:1 trans fatty acids, including 18:1 trans-9, trans-10, trans-11, the most abundant $(P<0.001$; Tables 3 and 4 , Figure 5), and both the total and most of the individual BCFA and 
Table 4. Results from ANOVA ( $F$-value and significance) for fatty acid groups and unsaturation indices in buffalo milk

\begin{tabular}{|c|c|c|c|c|c|c|c|}
\hline Trait $^{1}$ & \multicolumn{4}{|c|}{ DIM } & \multicolumn{2}{|c|}{ Parity } & $\mathrm{HTD}^{2} \%$ \\
\hline \multicolumn{8}{|c|}{ Group of fatty acids, $\mathrm{g} / 100 \mathrm{~g}$ of fatty acids } \\
\hline MUFA & 37.0 & $* * *$ & Quadratic $^{---}$ & $\mathrm{L}$ & 2.8 & $*$ & 56.7 \\
\hline PUFA & 10.9 & $* * *$ & Quadratic ${ }^{--}$ & $\mathrm{L}$ & 1.7 & NS & 69.2 \\
\hline SCFA & 26.1 & $* * *$ & Quadratic $^{+++}$ & $\mathrm{M}$ & 0.8 & NS & 22.1 \\
\hline OCFA & 7.8 & $* * *$ & Linear $^{+++}$ & $\mathrm{L}$ & 3.0 & $*$ & 36.9 \\
\hline n-6 PUFA & 5.8 & $* * *$ & Linear $^{+++}$ & $\mathrm{L}$ & 1.7 & NS & 78.8 \\
\hline n-3 PUFA & 9.3 & $* * *$ & Linear $^{+++}$ & $\mathrm{L}$ & 2.3 & NS & 32.1 \\
\hline n-6/n-3 & 1.9 & NS & - & & 1.8 & NS & 78.8 \\
\hline trans fatty acids & 10.5 & $* * *$ & Linear $^{+++}$ & $\mathrm{L}$ & 2.1 & NS & 71.2 \\
\hline trans fatty acids $18: 1$ & 6.0 & $* * *$ & Linear $^{+++}$ & $\mathrm{L}$ & 2.2 & NS & 74.3 \\
\hline $\mathrm{RA} /(\mathrm{RA}+\mathrm{VA})$ & 1.4 & NS & - & & 2.2 & NS & 35.0 \\
\hline
\end{tabular}

${ }^{1} c=$ cis $;=$ trans SCFA = short-chain fatty acids; MCFA = medium-chain fatty acids; LCFA = long-chain fatty acids; BCFA = branched-chain fatty acids; $\mathrm{OCFA}=$ odd-chain fatty acids; $\mathrm{RA}=$ rumenic acid; $\mathrm{VA}=$ vaccenic acid. SCFA included the 4:0, 6:0, 8:0, and 10:0 fatty acids; MCFA included all linear fatty acids from 11:0 to 16:1; LCFA included all linear fatty acids from 17:0 to 24:0; trans fatty acids included all trans fatty acids; trans fatty acids 18:1 included all trans isomers of 18:1.

${ }^{2}$ Herd/test date (HTD) effect expressed as proportion of variance explained by HTD calculated by dividing the corresponding variance component by the total variance.

${ }^{3+/-}$ : Refers to the trend direction of fatty acid trait LSM over lactation (linear, quadratic, or cubic); ${ }^{+/-} P<0.05 ;^{++/--} P<0.01 ;{ }^{+++/---} P<$ 0.001. E, M, L: highest percentages in early (E), mid (M), or late (L) lactation.

${ }^{*} P<0.05 ;{ }^{* *} P<0.01 ;{ }^{* * *} P<0.001$.

OCFA (Tables 3 and 4, Figure 6). Among the unsaturation indices, we observed linear increases for 10:1, 14:1, and 16:1 indices (Table 4, Figure 7a), and a cubic trend for 18:1 $(P<0.001$; Table 4$)$, with a decrease in the first 60 DIM followed by a gradual increase (Figure 7b).

\section{DISCUSSION}

\section{Detailed Milk Fatty Acid Profile of Buffalo Milk}

Values for milk production in buffaloes of the present study were lower than previous literature data (e.g., Tudisco et al., 2013). Similar MF percentages were described (e.g., Tufarelli et al., 2008; Salari et al., 2013), although sometimes higher values were reported (e.g., Tonhati et al., 2011), likely reflecting the effect of different management, feeding, and environmental conditions. These factors may also influence the fatty acid composition of buffalo milk (Secchiari et al., 2004; Varricchio et al., 2007). Indeed, our results only partially agreed with previous data on water buffalo (e.g., Tonhati et al., 2011; Zotos and Bampidis, 2014). Additionally, other studies were also often performed on a lower number of animals and different rearing conditions (e.g., Menard et al., 2010).
The buffaloes sampled for the present study were intensively reared with feeding and management conditions similar to those of dairy cows reared in close areas of northern Italy (Pegolo et al., 2016; Conte et al., 2016). Indeed, even if some variability in the dairy systems and animals productivity existed (midand high-producing cows), cows sampled in the cited studies were not grazed and were administered only preserved forages (no fresh forage) and concentrates, as in the buffaloes sampled in the present study. In addition, it is worth mentioning that those studies reported a qualitative (and not quantitative) analysis of milk fatty acid profile including a large number of fatty acid traits determined by GC analysis (as in the present analysis). Therefore, we draw some considerations in terms of similarities or differences (or both) between the 2 species, even though they should be considered purely indicative. Buffaloes and cows seemed to have comparable average milk fatty acid profiles (Tables 1 and 2), both characterized by considerable variability. On the other hand, the available comparative studies sometimes reported more pronounced variations, different results, or both (Blasi et al., 2008; Menard et al., 2010; Medhammar et al., 2012). Not relevant differences seemed to be detected in total SFA and UFA 

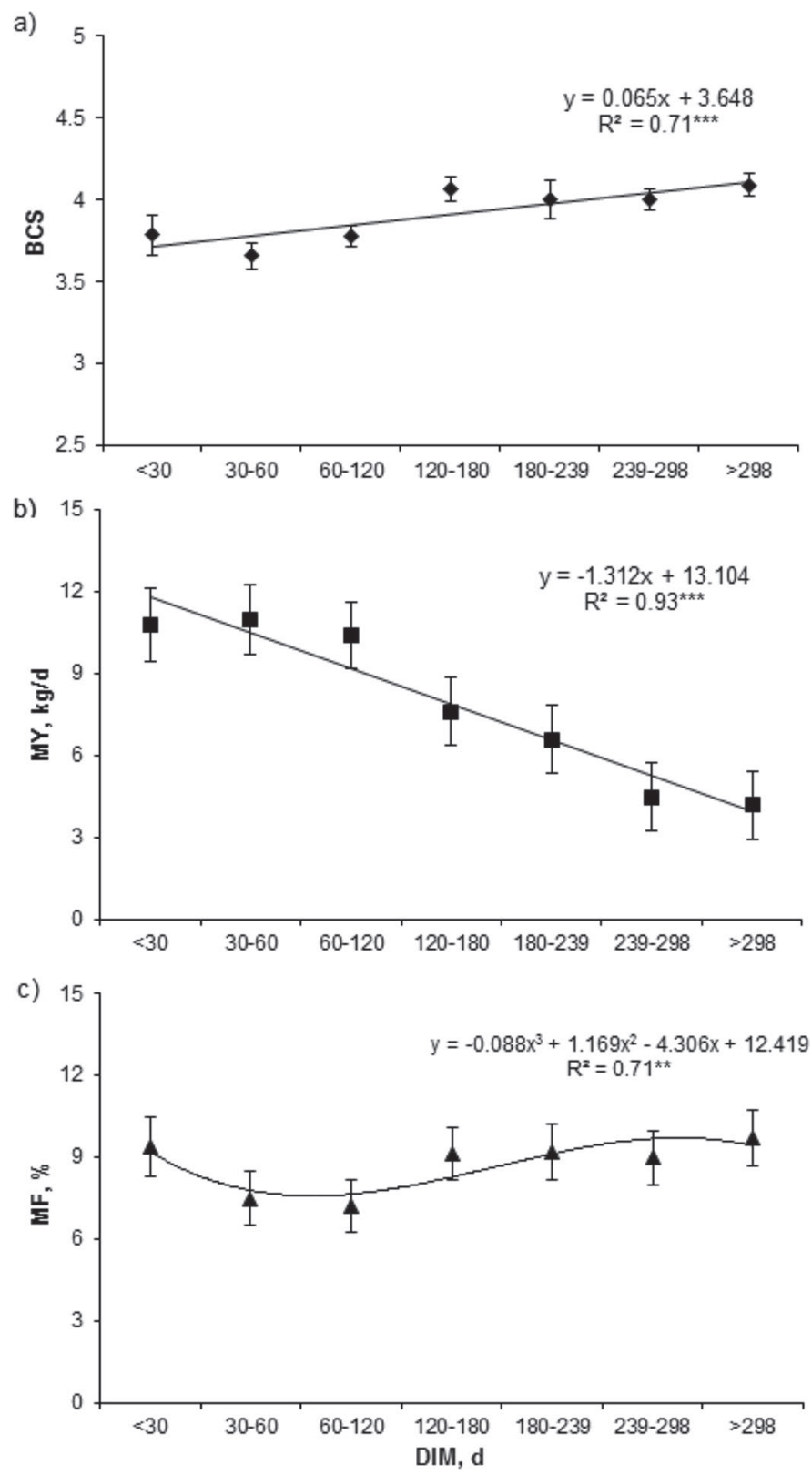

Figure 1. Least squares means and SE of (a) BCS, (b) milk yield (MY), and (c) milk fat (MF) across classes of DIM. ${ }^{* *} P<0.01,{ }^{* * *} P$ $<0.001$.

(MUFA+PUFA) proportions in milk of buffaloes and cows reared in north-east Italy. In contrast, previous data reported significantly higher SFA contents and lower UFA contents in buffalo milk respect to the milk of cows reared in the same herd (Menard et al., 2010). Buffalo milk had lower percentages of linoleic acid (18:2 cis-9,cis-12) and linolenic acid (18:3 cis-9,cis-12,cis-15) than bovine milk, different from previous findings (Blasi et al., 2008). On the other hand, our results partially agreed with those of Menard et al. (2010), who reported a lower percentage of linoleic acid in buffalo milk than in cow milk (but higher linolenic acid). Some differences in milk fatty acid composition could be due to the size of the MF globule (MFG, Martini et al., 2016). Buffalo milk has larger fat globules than cow milk due to its high MF content, and accordingly the relative proportion of polar lipids in buffalo $\mathrm{MF}$ is lower (Menard et al., 2010). Because linoleic and linolenic acid are preferentially esterified in polar lipids (Christie et al., 1987), variations in the contents of
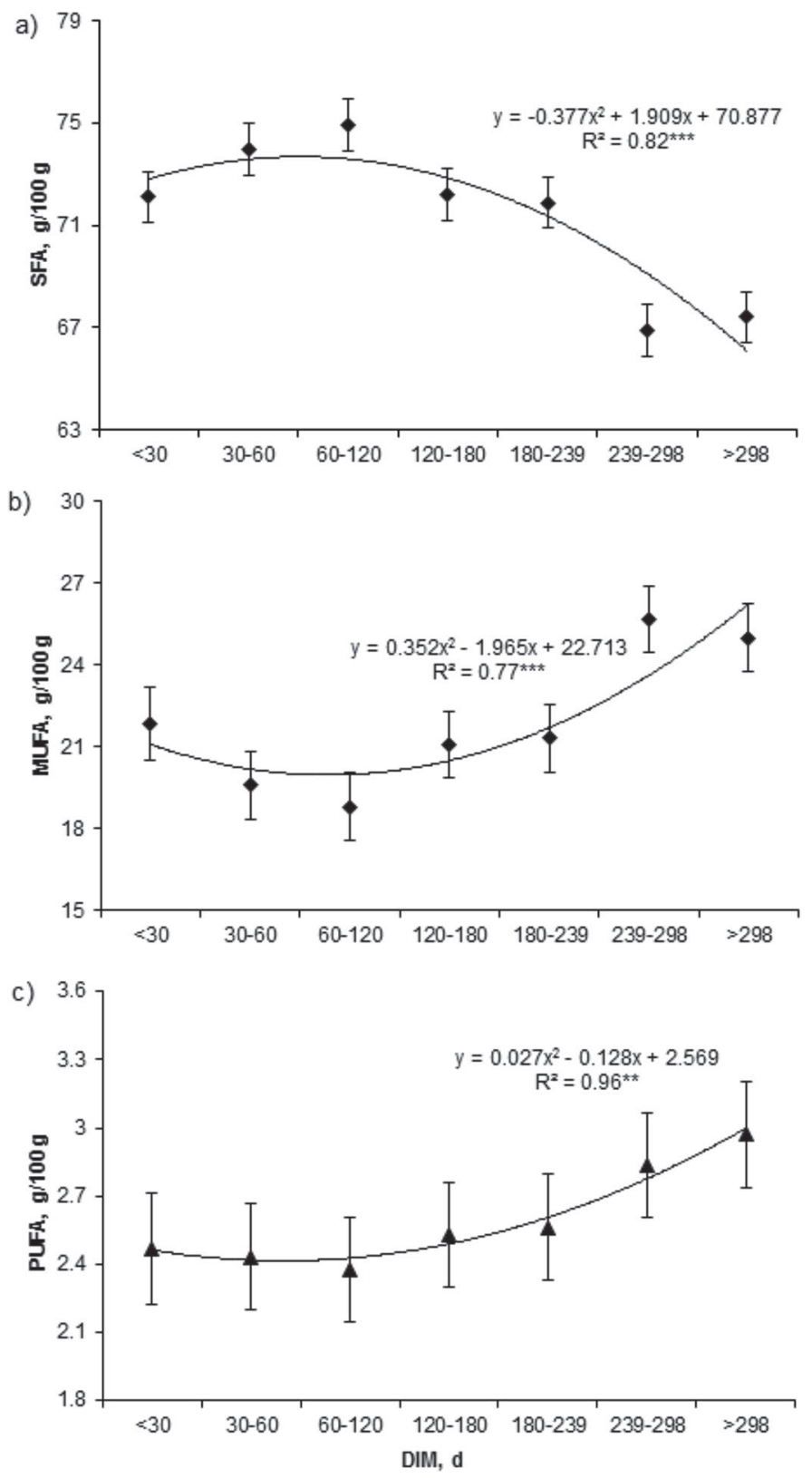

Figure 2. Least squares means and SE of (a) SFA, (b) MUFA, and (c) PUFA across classes of DIM. ${ }^{* *} P<0.01,{ }^{* * *} P<0.001$. 
these acids between buffalo and cow could be related to the different MFG diameter. However, in bovine milk, Lopez et al. (2011) observed no significant variation with MFG size in the individual content of linoleic and linolenic acids even if the ratio of linoleic acid/linolenic acid was significantly higher in larger globules. Higher amounts of n-6 fatty acids were detected particularly in Holstein cow milk (Conte et al., 2016) with respect to buffalo milk (mainly due to the higher percentage of linoleic acid), which consequently affected the n-6/n-3 ratio. Different values of $n-6 / n-3$ ratio were also reported in other studies (Blasi et al., 2008; Menard et
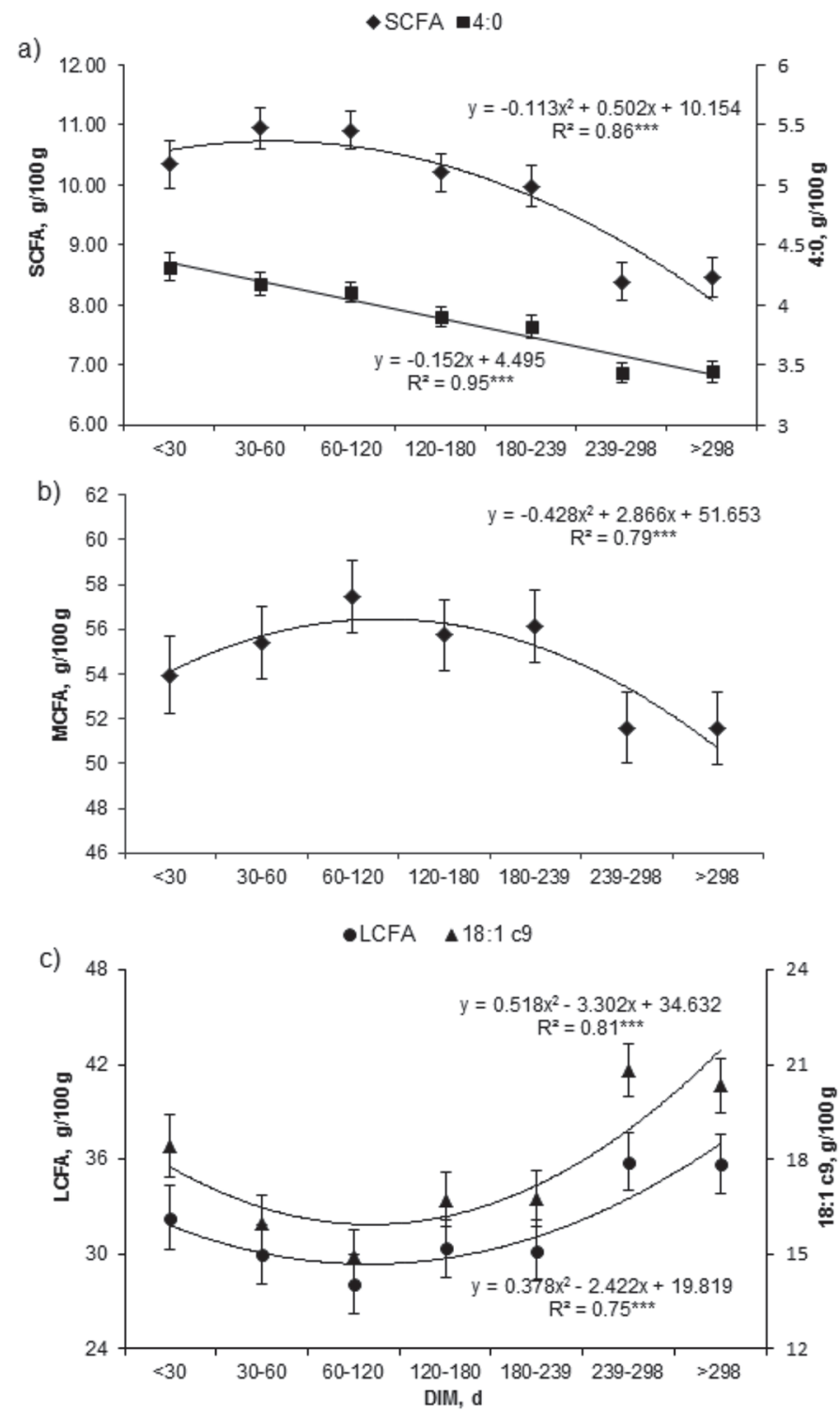

Figure 3. Least squares means (LSM) and SE of (a) short-chain fatty acids (SCFA) and 4:0 (data for 4:0 were plotted on a secondary axis), (b) medium-chain fatty acids (MCFA), and (c) long-chain fatty acids (LCFA) and oleic acid (LSM and SE for oleic acid were plotted on a secondary axis) across classes of DIM. ${ }^{* * *} P<0.001 . \mathrm{c}=$ cis.

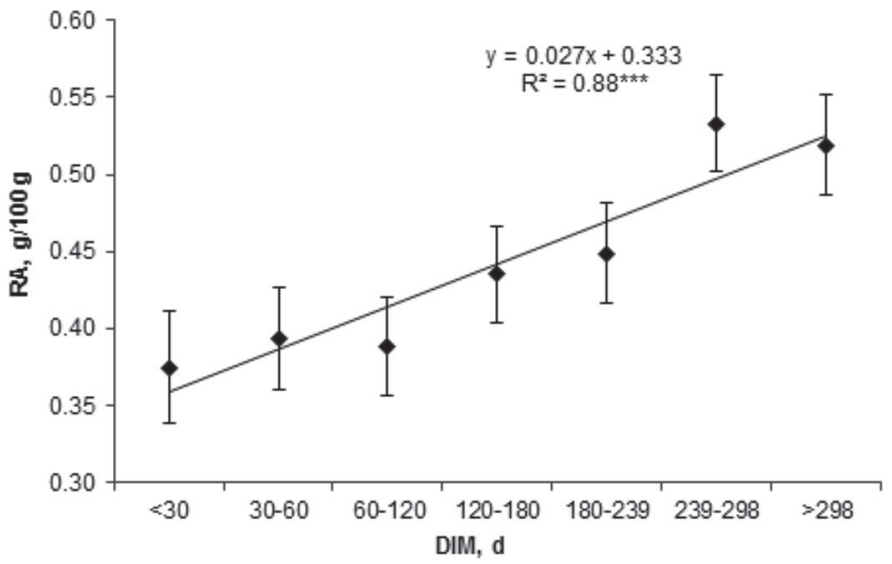

Figure 4. Least squares means and SE of rumenic acid (RA) across classes of DIM. ${ }^{* * *} P<0.001$.

al., 2010), which, however, considered only linoleic acid and linolenic acid as representative for the n- 6 and n-3 categories, respectively. We also found lower average RA proportions in buffalo milk (Table 1), in agreement with Talpur et al. (2008) but in contrast to Menard et al. (2010). Conjugated linoleic acid pools in milk may originate from either endogenous $\left(\Delta^{9}\right.$-desaturase) or ruminal sources (Kay et al., 2004). The factors affecting

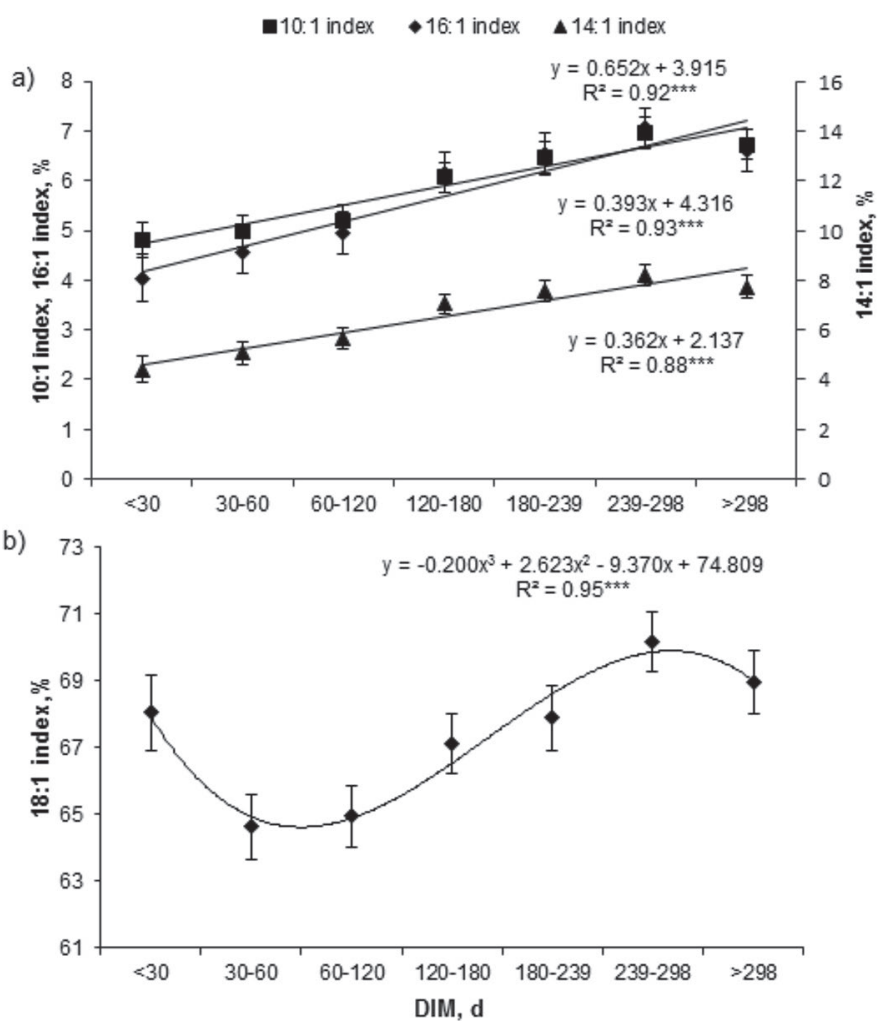

Figure 5. Least squares means and SE of the trans fatty acids (FA) across classes of DIM. ${ }^{* * *} P<0.001$. 


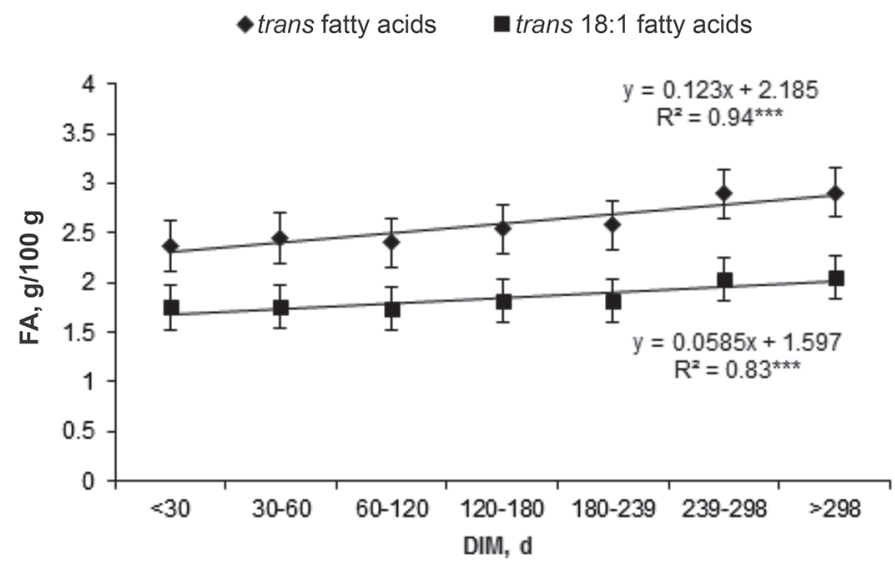

Figure 6. Least squares means and SE of the branched-chain fatty acids (BCFA) and odd-chain fatty acids (OCFA) across classes of DIM. ${ }^{* * *} P<0.001$. FA: fatty acids.

$\Delta^{9}$-desaturase activity have not yet been satisfactorily established, but probably include genetic factors, lactation period, and nutrition (Lock and Garnsworthy, 2003). However, although we observed some differences between the percentages of desaturation indices of buffalo and cow milk (Table 2), this does not provide sufficient and unambiguous evidence for a possible variation in SCD activity. There appeared to be no great differences between total trans and trans 18:1 fatty acid percentages in buffalo and cow milk, in disagreement with previous studies that found higher percentages in buffalo milk (Menard et al., 2010; Medhammar et al., 2012). According to US Food and Drug Administration (FDA, 2015) recommendations, trans fatty acid consumption must be kept as low as possible by limiting the intake of foods containing trans fatty acids formed during food processing. Indeed, trans fatty acids can

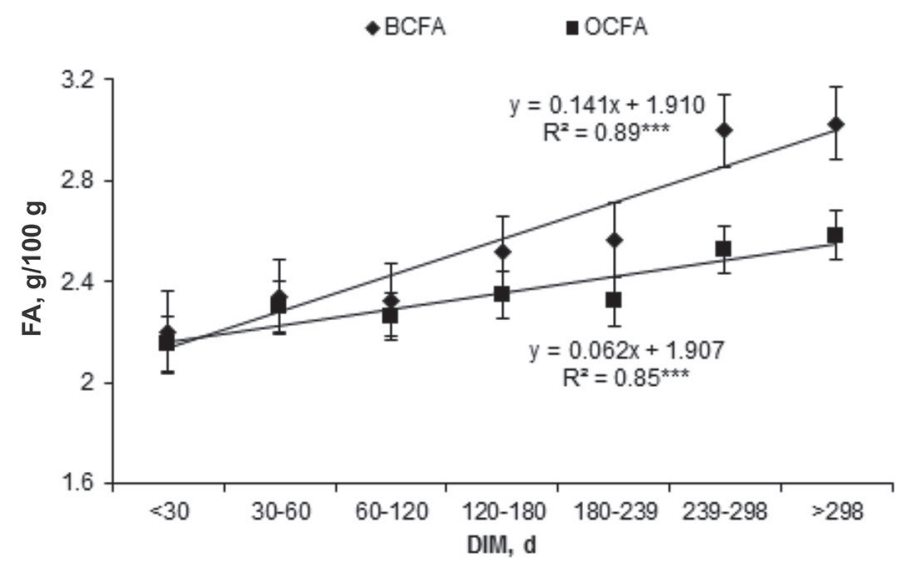

Figure 7. Least squares means and SE of the unsaturation indices across classes of DIM: (a) 10:1 index, 14:1 index, and 16:1 index (LSM and SE for 14:1 index were plotted on a secondary axis); (b) 18:1 index. ${ }^{* * *} P<0.001$. be divided into 2 groups: those that are industrially produced and may increase the risk of coronary heart disease (de Souza et al., 2015), and those that are ruminant derived and which may even reduce the risk of cardiovascular disease (Wang et al., 2010). The major industrially produced trans fatty acid in the food supply is elaidic acid (18:1 trans-9), whereas the major ruminant-derived trans fatty acid is VA (18:1 trans-11), which has also been shown to have anti-carcinogenic properties (Lim et al., 2014). Unfortunately, however, in the present study we were unable to accurately determine the individual percentages of elaidic acid and VA in all the buffalo milk samples. Finally, we found higher proportions of BCFA in buffalo milk than in cow milk, which may reflect differences in the rumen environment (Vlaeminck et al., 2006). Recent studies have also shown that BCFA (e.g., 15:0 iso) have anticancer properties (Yang et al., 2000). Interestingly, we found higher average percentages of 15:0 iso in buffalo milk than in cow milk (Table 1).

\section{Herd/Test Date and Animal Factors Affecting the Buffalo Milk Fatty Acid Profile}

The effects of animal factors, such as parity and stage of lactation, and the effects of HTD on the fatty acid composition of cow milk are well known (Kelsey et al., 2003; Craninx et al., 2008; Pegolo et al., 2016). We investigate here the effect of these factors on the fatty acid profile of buffalo milk.

The effects of HTD reflect variations in the farms sampled (i.e., differences in environmental conditions, feeding systems, and herd management), and the different dates on which test records were collected. The high incidence of HTD variance on total variance found in total PUFA, n-6 fatty acids, total trans fatty acids, and total trans 18:1 fatty acids likely reflects the effect of dietary factors on the content of these fatty acids. High percentages of HTD for these fatty acids were also reported in dairy cows (Heck et al., 2012; Patel et al., 2013; Pegolo et al., 2016), but we found an even higher incidence of HTD variance on total variance in the buffalo milk. On the other hand, the lowest variation in HTD observed for SCFA (Tables 3 and 4) is due to the origin of these fatty acids, which are mostly de novo synthetized in the mammary gland (Shingfield et al., 2013). The low contribution of HTD to the variance in the 10:1, 14:1, and 18:1 desaturation indices is in line with previous results for dairy cows (Pegolo et al., 2016) and confirms that they are less dependent on environmental effects.

Parity is another well-known factor affecting milk production and MF composition in dairy cows (e.g., Kelsey et al., 2003; Craninx et al., 2008). We did 
not, however, observe a significant difference in MY between primiparous and multiparous buffaloes (data not shown). Furthermore, the order of parity did not significantly affect the MF content of buffalo milk as it has been reported for cow milk (Sevi et al., 2000; Craninx et al., 2008). Only a few fatty acid traits were influenced by parity, and where the effects were significant, barely any difference was present between primiparous and multiparous buffaloes. A possible explanation for the differences between buffalo and cow milk could be that the average age of buffaloes at first calving is generally greater than the most common dairy cow breeds (more than 3 vs. 2.5 yr; AIA, 2014), which means there are probably only minor differences in BW and milk production between primiparous and multiparous buffaloes.

As expected, the stage of lactation significantly affected MY, BCS, and MF percentages (Table 3). The almost linear increase in BCS from the beginning of lactation seems to suggest that, unlike dairy cows, there are few changes in the mobilization of body reserves in buffalo (Coffey et al., 2003). It is likely that the variation in animal energy balance during lactation is less evident in buffaloes than in cows due to the lower amount of ME intake allocated for milk production. The trends observed for total SFA, MUFA, and PUFA were similar to previous observations in buffalo (Arumughan and Narayanan, 1981; Qureshi et al., 2015). In early lactation in buffalo, the effects of inhibition of de novo fatty acid synthesis (6:0 to 16:0) brought about by the uptake of blood LCFA from the mammary gland are less evident. The only exception was butyric acid (4:0), which is high at parturition and then decreased with advancing of lactation, likely due to a different synthetic pathway which is independent of malonylCoA (Palmquist, 2006). The main LCFA in milk [i.e., oleic acid (18:1 cis-9)] may originate not only from the mobilization of the adipose tissue but also from the diet and from the mammary desaturation of stearic acid. At the beginning of lactation, oleic acid was high due to lipid mobilization, then decreased reflecting the pattern of desaturase activity (18:1 index) and lipid mobilization decreased as well. In late lactation, it newly increased accordingly to the increase in desaturation activity, which was in line with previous results in buffalo (Tudisco et al., 2013) and cow (Soyeurt et al., 2008). Accordingly, we also observed an increase in RA as lactation progressed, whereas Tudisco et al. (2013) found a different pattern, the highest values being in the thirrd month and the lowest in the first and fourth months. All these findings may reflect a shorter period of negative energy balance in buffaloes than in cows due to their lower productivity and resulting reduced or null weight losses. Consequently, the milk fatty acid profile is probably less influenced by the mobilization of body reserves than it is in cows. It is also worth mentioning that the lactation period of the Mediterranean buffalo is $270 \mathrm{~d}$ (Catillo et al., 2002), compared with the cow's standard period of 305 d. Accordingly, Camargo Verdurico et al. (2012) found no marked variation in the profiles of SCFA, $<16$ carbon chain, $>16$ carbon chain, and all 18-carbon chain UFA in the first 8 wk of lactation in buffalo. Both trans fatty acids and trans 18:1 fatty acids showed slight variations during the first 120 DIM. Similarly, only slight variations in the concentrations of VA (the main trans 18:1 isomer) during the first $8 \mathrm{wk}$ of lactation in buffalo were found (Camargo Verdurico et al., 2012). The linear increases in BCFA and OCFA are in line with the literature on dairy cows (Craninx et al., 2008; Stoop et al., 2009). Because the BCFA content of MF is associated with the amount of forage intake (Vlaeminck et al., 2006), the proportions of BCFA may increase as lactation progresses in line with the buffalo's increased intake ability, and possibly with the amount of forage included in the ration.

\section{CONCLUSIONS}

This study presents a detailed analysis of fatty acid profile of Italian Mediterranean buffalo milk, including those fatty acids present in small concentrations that may have an effect on human health. We confirmed lactation stage and HTD as important sources of variation in the fatty acid profile of buffalo milk according to the specific fatty acid origin and metabolic pathway. Interestingly, the milk fatty acid profile in early lactation seems to be less affected by body energy reserve mobilization in buffaloes than in cows, probably due to a shorter period of negative energy balance. Parity, instead, had minor effects on the buffalo milk fatty acid profile. Therefore, these results may provide useful information about the nutrient composition of buffalo milk and its variation according to specific factors, which may be used to improve the technological and nutritional characteristics of buffalo milk.

\section{ACKNOWLEDGMENTS}

The authors thank the technical staff at the breeders associations of the provinces of Treviso and Padua and the region of Friuli-Venezia Giulia for providing milk-recording data and assisting in data collection, and the managers of the 6 dairy farms sampled for their collaboration. This research was supported by the University of Padua (Ricerca Scientifica fondi quota EX 60\%-60A08-7943/14). 


\section{REFERENCES}

Ahmad, S., F. M. Anjum, N. Huma, A. Sameen, and T. Zahoor. 2013. Composition and physico-chemical characteristics of buffalo milk with particular emphasis on lipids, proteins, minerals, enzymes and vitamins. J. Anim. Plant Sci. 23(Suppl. 1):62-74.

AIA. 2014. Associazione Italiana Allevatori (AIA) bollettino dei controlli della produttività del latte. Accessed Jun. 21, 2016. http:// www.aia.it.

Arumughan, C., and K. M. Narayanan. 1981. Influence of stage of lactation on the triacylglycerol composition of buffalo milk fat. Lipids 16:155-164.

Blasi, F., D. Montesano, M. De Angelis, A. Maurizi, F. Ventura, L. Cossignani, M. S. Simonetti, and P. Damiani. 2008. Results of stereospecific analysis of triacylglycerol fraction from donkey, cow, ewe, goat and buffalo milk. J. Food Compos. Anal. 21:1-7.

Camargo Verdurico, L., J. Rodrigues Gambra, J. Esler de Freitas Júnior, R. Villela Barletta, B. Conte Venturelli, R. D. Mingoti, T. H. A. Vendramini, and F. Palma Rennó. 2012. Evaluation of the milk fatty acid profile from Mediterranean buffalo cows in the first eight weeks of lactation. J. Buffalo Sci. 1:177-182.

Catillo, G., N. P. P. Macciotta, A. Carretta, and A. Cappio-Borlino. 2002. A. Effects of age and calving season on lactation curves of milk production traits in Italian water buffaloes. J. Dairy Sci. 85:1298-1306.

Christie, W. W. 2001. A practical guide to the analysis of conjugated linoleic acid (CLA). Inform 12:147-152.

Christie, W. W., R. C. Noble, and G. Davies. 1987. Phospholipids in milk and dairy products. J. Soc. Dairy Technol. 40:10-12.

Coffey, M. P., G. Simm, W. G. Hill, and S. Brotherstone. 2003. Genetic evaluations of dairy bulls for daughter energy balance profiles using linear type scores and body condition score analyzed using random regression. J. Dairy Sci. 86:2205-2212.

Colarow, L., M. Turini, S. Teneberg, and A. Berger. 2003. Characterization and biological activity of gangliosides in buffalo milk. Biochim. Biophys. Acta 1631:94-106.

Conte, G., A. Serra, P. Cremonesi, S. Chessa, B. Castiglioni, A. Cappucci, E. Bulleri, and M. Mele. 2016. Investigating mutual relationship among milk fatty acids by multivariate factor analysis in dairy cows. Livest. Sci. 188:124-132.

Craninx, M., A. Steen, H. Van Laar, T. Van Nespen, J. Martín-Tereso, B. De Baets, and V. Fievez. 2008. Effect of lactation stage on the odd- and branched-chain milk fatty acids of dairy cattle under grazing and indoor conditions. J. Dairy Sci. 91:2662-2677.

Dal Maso, M., F. Tagliapietra, M. Cattani, A. Fracasso, S. Miotello, and S. Schiavon. 2009. Characteristics of dairy farms in the north east part of Italy: Rations, milk yield and nutrient excretion. Ital. J. Anim. Sci. 8(Suppl. 2):295-297.

de Souza, R. J., A. Mente, A. Maroleanu, A. I. Cozma, V. Ha, T. Kishibe, E. Uleryk, P. Budylowski, H. Schünemann, J. Beyene, and S. S. Anand. 2015. Intake of saturated and trans unsaturated fatty acids and risk of all cause mortality, cardiovascular disease, and type 2 diabetes: Systematic review and meta-analysis of observational studies. BMJ 351:h3978.

Edmonson, A., I. Lean, L. Weaver, T. Farver, and G. Webster. 1989. A body condition scoring chart for Holstein dairy cows. J. Dairy Sci. 72:68-78.

FAOSTAT. 2013. Food and Agriculture Organization of the United Nations (FAO) statistical database. Accessed Jun. 21, 2016. http://faostat3.fao.org.

FDA. 2015. US Food and Drug Administration reports. Accessed Jun. 21, 2016. http://www.fda.gov/.

Hanaa, A. A., B. M. Manal, and A. Fathi. 2015. A study for comparison between immune status of dairy Egyptian buffaloes and the crosses of Egyptian-Italian buffaloes under the Egyptian environment. J Am. Sci. 11:53-56.

Heck, J. M., H. J. van Valenberg, H. Bovenhuis, J. Dijkstra, and T. C. van Hooijdonk. 2012. Characterization of milk fatty acids based on genetic and herd parameters. J. Dairy Res. 79:39-46.

Kay, J. K., T. R. Mackle, M. J. Alduist, N. A. Thomson, and D. E. Bauman. 2004. Endogenous synthesis of cis-9, trans-11 conju- gated linoleic acid in dairy cows fed fresh pasture. J. Dairy Sci. $87: 369-378$.

Kelsey, J. A., B. A. Corl, R. J. Collier, and D. E. Bauman. 2003. The effect of breed, parity, and stage of lactation on conjugated linoleic acid (CLA) in milk fat from dairy cows. J. Dairy Sci. $86: 2588-2597$.

Koba, K., and T. Yanagita. 2014. Health benefits of conjugated linoleic acid (CLA). Obes. Res. Clin. Pract. 8:e525-e532.

Lim, J.-N., J.-J. Oh, T. Wang, J.-S. Lee, S.-H. Kim, Y.-J. Kim, and H.-G. Lee. 2014. trans-11 18:1 vaccenic acid (TVA) has a direct anti-carcinogenic effect on MCF-7 human mammary adenocarcinoma cells. Nutrients 6:627-636.

Lock, A. L., and P. C. Garnsworthy. 2003. Seasonal variation in milk conjugated linoleic acid and $\Delta^{9}$-desaturase activity in dairy cows. Livest. Prod. Sci. 79:47-59.

Lopez, C., V. Briard-Bion, O. Menard, E. Beaucher, F. Rousseau, J. Fauquant, N. Leconte, and R. Benoit. 2011. Fat globules selected from whole milk according to their size: Different compositions and structure of the biomembrane, revealing sphingomyelin-rich domains. Food Chem. 125:355-368.

Martini, M., S. Salari, and I. Altomonte. 2016. The macrostructure of milk lipids: The fat globules. Crit. Rev. Food Sci. Nutr. 56:12091221.

Medhammar, E., R. Wijesinha-Bettoni, B. Stadlmayr, E. Nilsson, U. R. Charrondiere, and B. Burlingame. 2012. Composition of milk from minor dairy animals and buffalo breeds: A biodiversity perspective. J. Sci. Food Agric. 92:445-474.

Menard, O., S. Ahmad, F. Rousseau, V. Briard-Bion, F. Gaucheron, and C. Lopez. 2010. Buffalo vs. cow milk fat globules: Size distribution, zeta-potential, compositions in total fatty acids and in polar lipids from the milk fat globule membrane. Food Chem. 120:544-551.

Mir, Z., M. L. Rushfeldt, P. S. Mir, L. J. Paterson, and R. J. Weselake. 2000. Effect of dietary supplementation with either conjugated linoleic acid (CLA) or linoleic acid rich oil on the CLA content of lamb tissues. Small Rumin. Res. 36:25-31.

Palmquist, D. L. 2006. Milk fat: Origin of fatty acids and influence of nutritional factors thereon. Pages 43-93 in Advanced Dairy Chemistry, Volume 2: Lipids, 3rd ed. P. F. Fox and P. L. H. McSweeney, ed. Springer, New York, NY.

Patel, M., E. Wredle, and J. Bertilsson. 2013. Effect of dietary proportion of grass silage on milk fat with emphasis on odd- and branched-chain fatty acids in dairy cows. J. Dairy Sci. 96:390-397.

Pegolo, S., A. Cecchinato, J. Casellas, G. Conte, M. Mele, S. Schiavon, and G. Bittante. 2016. Genetic and environmental relationships of detailed milk fatty acids profile determined by gas chromatography in Brown Swiss cows. J. Dairy Sci. 99:1315-1330.

Pellattiero, E., A. Cecchinato, F. Tagliapietra, S. Schiavon, and G. Bittante. 2015. The use of 2-dimensional gas chromatography to investigate the effect of rumen-protected conjugated linoleic acid, breed, and lactation stage on the fatty acid profile of sheep milk. J. Dairy Sci. 98:2088-2102.

Qureshi, M. S., A. Mushtaq, S. Jan, and I. Rahman. 2015. Effect of age and lactation on milk fatty acid profile in dairy buffaloes. Buffalo Bull. 34:275-283.

Salari, F., I. Altomonte, and M. Martini. 2013. Buffalo milk: A case study of some parameters related to milk production. Large Animal Review 19:17-20.

Secchiari, P., G. Campanile, M. Mele, F. Zicarelli, A. Serra, M. Del Viva, and L. Amante. 2004. Fatty acid composition and CLA content of milk fat from Italian Buffalo. J. F. Hocquette and S. Gigli, ed. Indicators of milk and beef quality. EAAP Scientific Series, 112. Wageningen Academic Publishers, Wageningen, the Netherlands.

Sevi, A., L. Taib, M. Albenzio, A. Muscio, and G. Annicchiarico. 2000. Effect of parity on milk yield, composition, somatic cell count, renneting parameters and bacteria counts of Comisana ewes. Small Rumin. Res. 37:99-107.

Shingfield, K. J., M. Bonnet, and N. D. Scollan. 2013. Recent developments in altering the fatty acid composition of ruminant-derived foods. Animal 7:132-162. 
Siri-Tarino, P. W., Q. Sun, F. B. Hu, and R. M. Krauss. 2010. Metaanalysis of prospective cohort studies evaluating the association of saturated fat with cardiovascular disease. Am. J. Clin. Nutr. 91:535-546.

Soyeurt, H., F. Dehareng, P. Mayeres, C. Bertozzi, and N. Gengler. 2008. Variation of Delta 9-desaturase activity in dairy cattle. J. Dairy Sci. 91:3211-3224.

Stocco, G., C. Cipolat-Gotet, V. Bonfatti, S. Schiavon, G. Bittante, and A. Cecchinato. 2016. Short communication: Variations in major mineral contents of Mediterranean buffalo milk and application of Fourier-transform infrared spectroscopy for their prediction. J. Dairy Sci. 99:8680-8686. https://doi.org/10.3168/jds.2016-11303.

Stoop, W. M., H. Bovenhuis, J. M. L. Heck, and J. A. M. Van Arendonk. 2009. Effect of lactation stage and energy status on milk fat composition of Holstein-Friesian cows. J. Dairy Sci. 92:1469-1478.

Talpur, F. N., M. I. Bhanger, A. A. Khooharo, and M. G. Zuhra 2008. Seasonal variation in fatty acid composition of milk from ruminants reared under the traditional feeding system of Sindh, Pakistan. Livest. Sci. 118:166-172.

Tiezzi, F., A. Cecchinato, M. De Marchi, L. Gallo, and G. Bittante. 2009. Characterization of buffalo production of northeast of Italy. Ital. J. Anim. Sci. 8(Suppl. 2):160-162.

Tonhati, H., A. L. Lima, D. P. Lanna, G. M. de Camargo, F. Baldi, L. G. de Albuquerque, and J. M. Montrezor. 2011. Milk fatty acid characterization and genetic parameter estimates for milk conjugated linoleic acid in buffaloes. J. Dairy Res. 78:178-183.
Tudisco, R., M. Cutrignelli, S. Calabrò, M. Grossi, N. Musco, G. Monastra, and F. Infascelli. 2013. Milk CLA content and $\delta 9$ desaturase activity in buffalo cows along the lactation. Buffalo Bull. $32: 1330-1333$

Tufarelli, V., M. Dario, and V. Laudadio. 2008. Diet composition and milk characteristics of Mediterranean water buffaloes reared in South Eastern Italy during spring season. Livest. Res. Rural Dev. $20: 1-7$.

Varricchio, M. L., A. Di Francia, F. Masucci, R. Romano, and V. Proto. 2007. Fatty acid composition of Mediterranean buffalo milk fat. Ital. J. Anim. Sci. 6:509-511.

Vlaeminck, B., V. Fievez, A. R. J. Cabrita, A. J. M. Fonseca, and R. J. Dewurst. 2006. Factors affecting odd- and branched-chain fatty acids in milk: A review. Anim. Feed Sci. Technol. 131:389-417.

Wang, Y., M. M. Jacome-Sosa, D. F. Vine, and S. D. Proctor. 2010 Beneficial effects of vaccenic acid on postprandial lipid metabolism and dyslipidemia: Impact of natural trans-fats to improve CVD risk. Lipid Technol. 22:103-106.

Yang, Z., L. Shangpei, X. Chen, H. Chen, M. Huang, and J. Zheng. 2000. Induction of apoptotic cell death and in vivo growth inhibition of human cancer cells by a saturated branched-chain fatty acid, 13-Methyltetradecanoic acid. Cancer Res. 60:505-509.

Zotos, A., and V. A. Bampidis. 2014. Milk fat quality of Greek buffalo (Bubalus bubalis). J. Food Compos. Anal. 33:181-186. 